\title{
Teaching Journal: An Effective Tool for Reflective Practice in Teaching among English Language Teachers
}

\author{
Yifan Wang* \\ Huzhou University, Huzhou 313000, China \\ *Corresponding author: Yifan Wang, 823985248@qq.com
}

\begin{abstract}
Through teaching journals, teachers can actively conduct true and continuous record, description, reflection, and summary of experiences and teaching behaviors with reflection and research value in their own teaching activities in order to make progress in regard to their teaching skills and classroom presentations. This is an effective way and tool to improve English teachers' reflective practice in teaching along with their own professional development as well as to promote the role transformation as reflective teachers. Given the widespread concern of the reflective practice in teaching along with the fact that teaching journals are effective in reflective teaching, this paper explores this topic and suggests several implications for teaching via documentation and a case analysis of three samples obtained from an actual teacher's teaching journal.
\end{abstract}

Keywords: Teaching journal; English teachers; Reflective practice

Publication date: August 2021; Online publication: August 30, 2021

\section{Introduction}

In the current situation of the curriculum education reform in mainland China, teachers are faced with the role transformation from traditional teachers to novel researchers with research and innovation consciousness. This leads to the extensive attention from the public on reflective teaching as a good way to guide the role transformation of teachers. Reflective teaching is the development process of teachers' selfdissection, self-denial, as well as self-transcendence. It also includes teachers' reflective behavior on teaching so as to seek other methods to effectively achieve teaching objectives and improve teaching. As a method for reflection, teaching journal is the most important, convenient, and commonly used form and tool in the practice of reflective teaching ${ }^{[1]}$.

\section{Literature review}

As the pioneer of research on the reflection practice in education, Dewey treats reflection as "a positive, persistent, and careful consideration of any belief or supposed form of knowledge in terms of the grounds that support it ${ }^{[2]}$." Journal, as a way of self-expression, has been regarded as one of the effective tools for education and reflective teaching since long ago. Generally, with the enrichment of human knowledge and research, teaching journals are widely used by various scholars and experts. In foreign countries, a teaching journal is considered as a formal research, and not just a tool to promote teaching as well as professional development. In contrast, the situation is different in China although there are many teachers who use teaching journals in their practice. In this section, conceptual contributions of various scholars will be introduced from the definition, functions, contents, to the styles of teaching journals. 


\subsection{Definition and functions of teaching journals}

By searching the database of One Search on Hong Kong Baptist University (HKBU), it has been found that there is no fixed terminology for "teaching journal" among various scholars, in which it is interchangeable with other terminologies, such as teaching diary, reflective journal, journal writing, and so forth. Similarly, there is no unified definition for "teaching journal." Brookfield ${ }^{[3]}$ had once pointed out that teaching journals are used by teachers to regularly record about their teaching experiences and learnings, thus presenting themselves in a conscious and vivid way. He also defined that a teaching journal is not only a list of events which had happened in a teacher's life, but also the teacher's understanding about teaching assumptions via these events. However, the shortfall in his points is the ignorance of the characteristics, which include the reflectiveness and meaningfulness of teaching journals. In fact, teaching journals are treated as a habit and way to improve critical-thinking ability among teachers since they help teachers to contemplate about their teaching experiences in view of personal and contextual factors from different aspects as well as to review their understanding through record and discovery ${ }^{[4]}$. In addition, based on theoretical research and practical experiences in the field of English language teacher development, Richards and Thomas came to the point regarding teachers' reflection: teaching journals allow teachers to clearly understand their own thoughts and reflect their beliefs as well as teaching practices, which are helpful to teachers in order to strengthen their determination in solving problems and obstacles ${ }^{[1]}$.

Domestic scholars have also defined the meaning of teaching journal from the perspective of reflective teaching. Wang pointed out a relatively perfect explanation; that is, the teaching journal is a significant way for teachers to record their own teaching behavior, summarize the success and failure of teaching, as well as review and analyze the whole teaching process to improve their self-development, teaching art, and selfworth ${ }^{[5]}$. However, there are still loopholes in this expression, of which it fails to show the initiative and continuity of writing in teaching journals. Zhao added that writing in a teaching journal is like a dialogue between a teacher with himself or herself, in which it provides a good space for the teacher to reflect, in addition to being a written description and feedback of teaching experiences ${ }^{[6]}$. At present, the generally and commonly used local definition of teaching journal is that teaching journal is a tool by which teachers can conduct a continuous real record and description of their experiences, which carry reflection and research value in their teaching activities in a positive and active way; on this basis, teachers can critically understand and recognize their teaching journals so as to constantly update concepts, increase their skills, and promote professional development.

\subsection{Contents of teaching journals}

There are many things that need to be recorded by teachers in a teaching journal. The contents of teaching journals are not presupposed but generated by teachers' induction and summary after actual teaching practice and reflection. In the United States, the academic tradition of teaching reflection classifies the contents of teaching reflection from the perspective of curriculum orientation, which focuses on learning contents, teaching contents, teaching strategies and methods, students, as well as social environment ${ }^{[7]}$; resulting in various opinions among different scholars about the contents of the journal. Richards and Lockhart proposed that the contents of teachers' reflection ought to include the teachers' awareness and decision-making, teachers' role, learners' description, classroom structure, classroom activities, and classroom language ${ }^{[8]}$. Josh Boyd and another researcher claimed that the most basic reflective journal should be concerned with the practice and technical level in teaching, and they recommended three dimensions of reflection while writing in teaching journals; namely, descriptive, comparative, and critical [9]. Walker reported that the contents of a teaching journal are concerned with the enhancement of reflection, critical thinking, and expression of feelings ${ }^{[10]}$.

The above views on the contents of teaching journals have been agreed on by many scholars locally. 
In the book, Reflective Teaching, Jin proposed that for the contents of teaching journals, teachers can record their successful practices and failures, as well as events and learning experiences ${ }^{[11]}$. Wang stated that the contents of a teaching journal should include six aspects, which include the success and the inadequacy in teaching, teaching inspiration, students' innovation, individual differences, as well as the reflection on and design for future teaching ${ }^{[5]}$. Li summarized that the contents of a teaching journal have two categories: descriptive and reflective, which often intersects and complements each other ${ }^{[11]}$. Descriptive teaching journal refers to teachers' declarative records of meaningful events and personal feelings during teaching, while the reflective one refers to teachers' reflection on teaching events.

\subsection{Characteristics and styles of teaching journals}

Generally speaking, teaching journals have the characteristics of immediacy, regularity, objectivity, description, and reflection. Among them, description requires recording in a simple, narrative, and descriptive way ${ }^{[9]}$. As for the style, there is no fixed format or requirements for teachers when writing in teaching journals. Each teacher can record in his or her own way and freely display individual writing styles and characteristics ${ }^{[4]}$.

To sum up, teaching journals serve as an effective tool for reflective practice in teaching. The views above clarify that the contents should mainly include teachers' beliefs, teaching methods, evaluation, and so on. In this research, the standards that were applied to analyze the reflective contents of the teachers are based on Wang's version ${ }^{[5]}$.

\section{Case analysis}

In this section, a critical analysis and discussion based on three journal samples related to the actual teaching context will be conducted. Voluntary consent has been obtained from this teacher.

\subsection{Presentation of the samples from a teaching journal}

Three samples from a teaching journal belonging to an English teacher, Miss Y, during her two-month teaching period, will be shown below. They include her reflection on the English subject teaching knowledge, classroom teaching, and teaching concept. Miss Y is a senior high school grade two English teacher who has been teaching for two years.

Sample 1:

12 ${ }^{\text {th }}$, April
Today's lesson is about the reading text of unit 5 "Canada - the true north". In warming-up,
students are not actively involved. The main reason is that students don't know much knowledge and
vocabulary about Canada, which makes them afraid to speak. Although I have provided some words
in advance, they still feel difficult, so that the effect of the whole warning-up step is not as expected.
In view of this situation, the measures I take in class are to encourage students to open up and
participate in interaction through the guidance of teachers, and then use collective discussion and
teacher-student discussion. The inspiration of this teaching situation for my future teaching is: if a
unit learning involves a specialized theme (such as national, environmental protection, sports, etc.),
teachers should let students collect and understand relevant vocabulary in advance in the form of
homework, so as to decrease the burden of classroom and improve the teaching effect.


In this sample, Miss Y first evaluated the warm-up session during her classroom teaching, in which the students' participation was poor. Then, she analyzed the reasons for this situation: students have inadequate knowledge and vocabulary in relevant aspects. Finally, the inspiration for future teachings is that if a unit involves a specific theme, teachers should encourage students to preview, learn, and understand the relevant vocabulary in advance.

Sample 2:

$30^{\text {th }}$, April
The teaching objective of this class is to let students to achieve the effect of consolidating
vocabulary, through the completion of the practice of selecting words and filling in blanks and the
teacher's explanation and analysis. However, I found that students do not have a solid grasp of words,
especially for the part of speech is vague. This shows that students have not fully realized the
importance of part of speech in vocabulary learning and are still satisfied with the spelling and
meaning they pursued in middle school when they memorize words. In the future, I should further
urge students to review words and strengthen the guidance of learning methods, so as to achieve the
purpose of learning.

It can be appreciated in the teaching journal that Miss $\mathrm{Y}$ has enhanced the understanding and analysis of students' learning characteristics, learning situations, as well as their learning needs in her reflection on classroom teaching. For example, through the review and reflection of her students' performance in class, problems and difficulties in vocabulary learning were noted. She then suggested solutions to counter these problems; however, they are not in-depth.

Sample 3:

$21^{\text {st }}$, May

Today is a writing class. When expanding the vocabulary of the hotel, I put forward a guide to let the students think about the description of the hotel in the direction of metaphor. I think the answer is quite simple when preparing for class. Because delicious restaurants make people feel happy and satisfied, it is better to use heaven, paradise and other words as metaphors. But I am surprised by the reaction of the students, their thinking do not spread. Although in the end, I succeed in inspiring and guiding students' thinking. The students say more ways of expression, and I also phrase some students who did not speak very correctly. I think it is common that different students have different understandings and ideas, especially in the class of thinking expansion, and there is nothing wrong with this understanding. Therefore, I reflect on the previous teaching and find that the process of language learning, teaching and understanding are not the just like science and engineering subject which owns one answer for one question. I often tell students that there is no fixed answer to a question I ask, and understanding varies from person to person. This can encourage students to think more. 
In this sample, Miss $\mathrm{Y}$ formed a teaching concept through reflection: teachers should encourage students to actively think, and not force them to accept the teachers' answers. Only in this way, students' learning initiative and ability of independent learning can be cultivated.

\subsection{Critical analysis}

Based on the above three samples, it is clear that Miss Y did conduct a reflection process of "evaluating teaching - analyzing reasons - obtaining enlightenment." This kind of reflection process is also a learning process for teachers in their understanding of teaching, to develop teaching knowledge, as well as teaching outlook.

Teaching journals show the characteristics of foreign language discipline and provide a platform for English language teachers to reflect and cultivate their awareness of reflection on teaching. As Jung proved in his research, reflection tasks such as journal writing serve as a chance for teachers to self-examine in order to identify the aspects that require improvement in their teaching practice, thus modifying their existing beliefs of teaching. For a language subject, English teachers should not only explain the relevant language knowledge, but also pay attention to the cultivation of students' ability to use the language in terms of ideology, emotions, and skills in the whole teaching process; during which many spontaneous collisions and frictions in language, thoughts, and emotions will appear, bringing many unexpected flash points. If teachers do not record their reflection in time, they will fade and eventually disappear because of the passage of time. For example, in Sample 3, students express different words, which is not expected in the teaching design, but it is a flash point during class. The reason behind this is worthy of reflecting. By actively reflecting on the teaching behavior, writing, and summarizing in teaching journals, teachers can timely adjust their teaching plans, combine with the development of the society, innovate thinking and teaching, as well as effectively foster their awareness and habit of reflecting.

Additionally, teaching journals are intrinsically a form of reflection, in which English language teachers' ability of reflection will be exercised and the motivation for reflection will be promoted. Through teaching journals, teachers are reminded of the aspects that require suitable adjustments and encourage the design of teaching activities for students in the future. For example, in Sample 1, the teacher reflected on the success and inadequacies of her teaching, their reasons, the characteristics of students' learning, and so on while gaining inspiration for future teaching designs. Meanwhile, through writing in teaching journals, it promotes teachers' thinking and understanding of teaching as well as leads teachers to a certain level of reflection; for example, understanding the complex points of in-depth teaching ${ }^{[14]}$ as well as creating connections between theoretical and practical issues. In addition, teachers would make efforts to justify their own views in their teaching journals as a result of being challenged by comments or doubts from other educators, thus further learning on how to reflect on issues.

However, there are certain issues and limitations related to teaching journals. For example, the failure of teachers to distinguish the difference between describing and reflecting in their journal writing restricts the contributions of the effort in fostering awareness and achieving higher levels of reflection ${ }^{[15]}$. For example, in Sample 3, Miss Y used too many narratives at the beginning, and the reflective content is relatively scarce; the whole article is only a reflection on her own teaching outlook rather than the reasons for such performance of her students in regard to classroom interactions. As for Sample 2, she failed to move beyond the reasons of her students' poor performance in vocabulary learning as she did not reflect deeply on how to adjust in future teaching. Teaching journals should not simply summarize an experience while thinking at the surface level, otherwise, the reflection will be meaningless. In addition, it can be appreciated that in her teaching journal, Miss Y only focused on her own reflection and summary without mentioning anything about the reflection from learning and communicating with other teachers. 


\section{Implications and conclusion}

This section discusses the implications of how teaching journals can be made more fruitful based on the analysis in the previous section. Thereafter, a brief conclusion will be presented.

\subsection{Implications}

Problems related to the lack of depth in teaching journals can be attributed to the fact that teachers have not received systematic training to write in teaching journals. Therefore, to begin with, it is necessary for schools to provide training for teachers. Reflection cannot be left to take care of itself; it deserves to be taught and teachers ought to be trained, so that it can be employed in the authentic context of the classroom [2]. In addition, given that the contributions of teachers' collaborative reflection to their professional development have been widely acknowledged ${ }^{[16]}$, it is an excellent suggestion to observe peer teaching and participate in peer exchange salon. Through these collaborative activities, another opportunity would be opened up for teachers to share and read each other's journals as well as to provide feedbacks while expanding subjective understanding of issues about English language teaching (ELT) and enriching the contents of their own teaching journals as they benefit from the ideas and experiences of their peers.

Besides, increasing the content proportion of reflection in teaching journals is also recommended. Only with in-depth and detailed reflection, then teachers can understand the nature of the problems, thus correcting them. Therefore, teachers should write more reflection opinions in teaching journals. Specifically speaking, when recording descriptive contents, it is better to leave some space for reflective and evaluative contents. On top of that, the most important thing is that teachers must timely and attentively reflect on their behavior in actual teaching, as well as connect with their past experiences to optimize ideas in order to reach new heights, improve their teaching levels, and ensure that their teaching journals are not limited to piecemeal experiences and solutions to local problems.

\subsection{Conclusion}

This paper tried to explore teaching journals as an effective reflective tool based on the analysis of authentic samples and suggested some implications for further studies and the application of teaching journals on reflection. In a word, teaching journals are true records of the continuity of teachers' thoughts and behaviors, in which they are effective tools for teachers to examine, reflect, analyze, and solve the puzzles in the teaching practice. Through teaching journals, English language teachers can grasp the teaching situation in time, determine teaching ideas or methods that are worth affirming and advocating, as well as constantly improve them. Although teachers' teaching journals lack depth and fail in terms of achieving a perfect proportion of reflective content, they can be improved by systematical training, peer-to-peer communication, interactive workshops, and other awareness-raising activities on reflection.

\section{Disclosure statement}

The author declares that there is no conflict of interest.

\section{References}

[1] Richards JC, Farrell TSC, 2005, Professional Development for Language Teachers: Strategies for Teacher Learning, Cambridge University Press, New York, 68-83.

[2] Shadi D, Hassan SA, 2019, EFL Teachers' Reflective Journal Writing: Barriers and Boosters. Iranian Journal of Language Teaching Research, 7(3): 71-90.

[3] Brookfield SD, 1995, Becoming a Critically Reflective Teacher, Jossey-Bass, San Francisco, CA, 1- 
19.

[4] Lee I, 2007, Preparing Pre-Service English Teachers for Reflective Practice. ELT Journal, 61(4): 3219.

[5] Wang Y, 2005, The Writing of Teaching Reflection Journal. Modern Primary and Secondary Education, 11: 73-4.

[6] Zhao S, 2009, Teaching Journal: An Effective Approach for Foreign Language Teachers to Conduct Reflective Teaching. University Education Science, 2: 56-9.

[7] Zeichner KM, Liston DP, 1996, Reflective teaching: An introduction. Lawrence Erlbaum, Mahwah, New Jersey, 36-49.

[8] Richards JC, Lockhart C, 2000, Reflective Teaching in Second Language Classrooms, People's Education Press, Beijing, China, 5-7.

[9] Boyd J, Boyd S, 2005, Reflect and Improve: Instructional Development Through a Teaching Journal. College Teaching, 53(3): 110-4.

[10] Walker S, 2006, Journal Writing as a Teaching Technique to Promote Reflection. Journal of Athletic Training, 41(2): 216-21.

[11] Jin Y, 2006, Reflective Teaching, Sichuan Education Press, Sichuan, China, 220-34.

[12] Li Y, Li X, Hong Z, 2013, Teaching Journal: An Important Way to Cultivate Reflective English Language Teachers. Journal of Teaching and Management, 3: 54-5.

[13] Jung J, 2012, The Focus, Role, and Meaning of Experienced Teachers' Reflection in Physical Education. Phys Educ Sport Pedagogy, 17(2): 157-75.

[14] Degago AT, 2007, Using Reflective Journals to Enhance Impoverished Practicum Placements: A Case in Teacher Education in Ethiopia. Teaching Education, 18(4): 343-56.

[15] Abednia A, Hovassapian A, Teimournezhad S, et al., 2013, Reflective Journal Writing: Exploring InService EFL Teachers' Perceptions. System, 41(3): 503-14.

[16] Danielowich RM, 2012, Other Teachers' Teaching: Understanding the Roles of Peer Group Collaboration in Teacher Reflection and Learning. The Teach Educator, 47(1): 101-22. 